\title{
MEU BAOBÁ GENEALÓGICO: \\ Histórias e memórias de mulheres que me sustentam
}

MY GENEALOGICAL BAOBAB:

Stories and memories of women who support me

\section{GENEALOG BAOBA:}

Historias y recuerdos de mujeres que me apoyan

RESUMO: Este texto nasce inicialmente elaborado para uma apresentação no Ler, festival do leitor, realizado na Biblioteca Parque e no Campo de Santana, no dia 20 de novembro, do corrente ano, no Rio de Janeiro. Integrei a mesa intitulada escrituras negras: ancestralidade, memória e autoconhecimento. Tive a grande honra de compartilhar a fala com as professoras Carolina Rocha e Janete Santos Ribeiro. A simbologia e representatividade da data - onde é celebrado o dia da Consciência Negra - me levaram a desejar homenagear as mulheres negras que tem contribuído para minha trajetória acadêmica e de vida. Interessava-se também oportunizar reflexões, embora breves, sobre a história recente do movimento de mulheres negras no Rio de Janeiro. Venho, há algum tempo, me debruçando a respeito dos estudos e reflexões sobre autoetnografia. Assim, decidi recorrer - de forma inspiradora, embora sem citar os autores - a esta teoria ainda pouco aprofundada, no Brasil, para dar apoio às minhas reflexões sobre as mulheres com as quais tenho dialogado e assimilado seus conhecimentos, desde a infância.

PALAVRAS-CHAVE: Mulheres negras. Identidade. Feminismo negro.

ABSTRACT: This article was initially prepared for a presentation in LER reader festival, held at the Biblioteca Parque in Campo de Santana, on November 20th, this year, in Rio de Janeiro. I joined the table entitled black writing: ancestry, memory and self-knowledge. I had the great honor of sharing the talk with teachers Carolina Rocha and Janete Santos Ribeiro. The symbolism and representativeness of the date - when Black Consciousness Day is celebrated - led me to wish to honor the black women who have contributed to my life and academic trajectory. There was also an opportunity for reflections, although brief, on the recent history of the black women's movement in Rio de Janeiro. So I decided to appeal - inspiringly, but without citing the authors - to this theory

Submetido em: 27/11/2019 - Aceito em: 19/12/2019 - Publicado em: 28/12/2019.

${ }^{1}$ Doutora em Ciências Sociais (UERJ). Professora do Programa de Pós-graduação em Educação da Universidade Federal do Ceará (UFC) e no Programa de Pós-Graduação em Educação, Contextos Contemporâneos e Demandas Populares (PPGEduc), da UFRRJ. Professora associada da Universidade Federal Rural do Rio de Janeiro (UFRRJ).Pos doutora pela Pontifícia Universidade Católica do Peru (PUCP). 


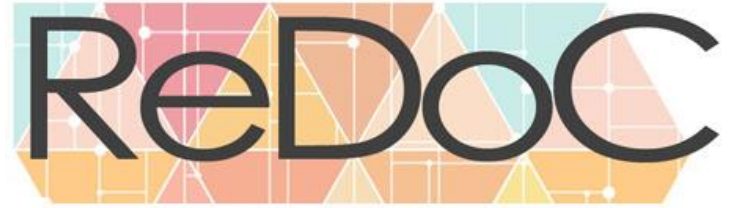

Revista Docência e Cibercultura

still little used in Brazil, to support my reflections on the women with whom I have dialogued and assimilated their knowledge since childhood.

KEYWORDS: Black women. Identity. Black feminism.

RESUMEN: Este texto está diseñado originalmente para una presentación en el LER festival de lectores, celebrado em 20 de noviembre, de este año, en Río de Janeiro. Formaba parte de la tabla titulada Escrituras negras: ascendencia, memoria y autoconocimiento Tuve el gran honor de compartir la charla con las maestras Carolina Rocha y Janete Santos Ribeiro. El simbolismo y la representatividad de la fecha - donde se celebra el Día de la Conciencia Negra - Me llevaron a desear honrar a las mujeres negras que han contribuido a mi trayectoria académica y de vida. También hubo una oportunidad para reflexionar, aunque breve, sobre la historia reciente del movimiento de mujeres negras en Río de Janeiro. Llevo algún tiempo escribiendo sobre estudios y reflexiones sobre autoetnografía. Así que decidí apelar - para inspirarme aunque sin citar a los autores - a esta teoría aún poco explorada, en Brasil, para apoyar mis reflexiones sobre las mujeres con las que he dialogado y asimilado sus conocimientos desde la infância.

PALABRAS CLAVE: Mujeres negras. Identidad. Feminismo negro.

\section{MEU BAOBÁ GENEALÓGICO: Histórias e memórias de mulheres que me sustentam}

Meu Baobá é uma árvore com um tronco, três galhos principais e muitos outros que se estendem. Afinal, assim é esta árvore africana que cresce ereta, vive centenas de anos e tem folhas e galhos bem lá na ponta. É como se o que está em cima fosse puxando o longo, encorpado e frondoso caule. Assim sou eu. Sigo crescendo ao sabor da esticada de minhas ramas.

Um dos galhos mais fortes é composto por minha avó, o outro por minha mãe, Dona Dorva (Quandalá de Oxum) e o terceiro tem várias ramificações onde estão as mulheres integrantes do movimento de mulheres negras, de minha geração, no Rio de Janeiro.

Vovó Maria Ambrósia era daquelas que adorava andar com os pés no chão, sentindo a terra. Aprendeu isto de infância, ao trabalhar na roça. Recentemente, minha prima Leninha - mulher negra, única de pele clara numa família de pretos retintos, que ainda jovem pintou os cabelos de negro, para não ser a "loira" da família - usou uma expressão que me impactou: Vovó Maria era uma mulher sábia. Assim o era. Tratava-me como a netinha que estava sempre pronta para sua atenção. Aprendi a ler com ela. Quando terminei o curso de professora primária, aos dezoito anos, ela disse: - Hoje ela é professora, mas, quem ensinou a ler, fui eu. 


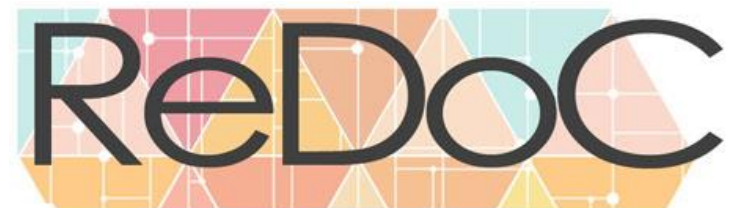

Revista Docência e Cibercultura

Sou de uma geração em que se aprendia a ler com as avós. No meu tempo, esta cultura estava quase chegando ao fim, nas franjas e periferias das cidades. Mas, consegui me beneficiar dela. Ainda foi possível chegar à escola já sabendo ler jornais - a Luta Democrática, era o mais popular da época - escrever e contar até cem, aos meus seis anos de idade.

Estudar com vó era mais que ser alfabetizada com as letras. Muitos outros ensinamentos eram espargidos em nossas tenras idades. Recebíamos, acima de tudo, amor, atenção e experiência de vida. Eu fui alfabetizada como quem fingia que estava na escola. Nosso terreno era daqueles em que há diferentes planos. Nossa casa ficava na frente. Quando eu pegava o caderno e subia as escadas, para encontrar vovó, eu dizia: - Mãe, já vou para a escola. Era bom brincar de saber ler e escrever.

Vovó era daquelas senhoras mineiras que tudo resolvia com rezas e chá de alguma folha do quintal ou dos matos que ainda existiam, nos terrenos baldios, em torno de casa. Meio calada diante dos desconhecidos e contadeira de casos entre amigos e família. Viveu numa casa nos fundos de nosso quintal até pelo menos meus dez anos, no Bairro Copacabana, em Duque de Caxias, Rio de Janeiro.

Depois, foi morar em outro bairro, no Jardim Metrópolis, em São João do Meriti. Lá, era perto da casa de minha Tia Marina e meus quinze primos. Podia-se ir de ônibus da minha casa para a de minha tia, mas vovó preferia ir andando. - O ônibus demora tanto que a pé, chega mais rápido, dizia ela. Quando se mudou, surgiu a oportunidade para eu dormir em sua casa - quando meu pai permitia - e compartilhar a diminuta cama que só cabia ela. Mas, que se alargava e recebia a nós duas. Uma para cada lado. Eu ficava estática, para não chutar sua cabeça enquanto dormia.

Mais tarde, esta experiência foi importante nas viagens e atividades do movimento de mulheres negras. Muitas vezes tínhamos que compartilhar estreitos leitos ao final das reuniões de vários dias e noites, no processo de organização de nossas atividades políticas. Éramos muitas compartilhando pouca estrutura. Assim, acabávamos em casa de alguma companheira que nos abrigava nos bairros, cidades e regiões brasileiras. Era a época anterior aos financiamentos nacionais ou internacionais. Não podíamos arcar com despesas de hotéis. 


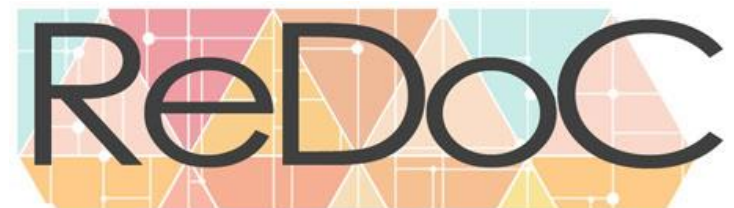

Revista Docência e Cibercultura

Visitar vovó era a oportunidade de comer o melhor feijão do mundo. Uma iguaria de feijão, arroz, angu, couve e carne se tornava o melhor presente que vovó me podia oferecer. Enquanto escrevo sinto o sabor e aroma daquele prato especial em minha memória afetiva. Eu recebia feliz aquela honraria. Uma pequena casa, muito simples e com poucos móveis oferecia um palácio de oportunidades de estar com vovó só para mim. Por alguma razão, os primos e primas não a visitavam quando eu estava lá. Hoje, penso que Tia Marina dizia para que nos deixassem a sós. Afinal, ela estava ali, para eles e elas, todos os dias.

Na adolescência, era com ela que conversava sobre os namorados reais ou imaginados, por uma jovem que desde cedo experimentava o que depois se convencional chamar por solidão da mulher negra. Sempre fui daquelas meninas, jovens e mulheres de quadris largos. Isto foi uma tormenta para mim e um estímulo à fantasia dos homens de diferentes idades. O medo deles se fazia presente em mim. Vovó ouvia as histórias e dava conselhos.

O outro galho, do meu Baobá Genealógico é mamãe, Dona Dorva. Mulher de Oxum com todas as características de doçura e fortaleza quando se fazia necessário. Sou aquariana. Daquelas que acredita que tudo quer, tudo pode e tudo enfrenta. Mamãe me deu rumo. Fez-me entender os limites e equilíbrios da vida. Eu teria sido das que tudo começa e nada termina. Ela me fez ter planos e sonhos. Todos compartilhados com a realidade. Sou das que briga e fala tudo a todo o momento. Sua voz me dizendo "A franqueza quando é demais muda de nome, passa a ser falta de educação”, faz eco em meus ouvidos vinte anos após seu falecimento. Ajudou-me a vislumbrar oportunidades onde eu não percebia sua existência. Revelou-me a importância de exercitar o silêncio, quando surgisse a oportunidade.

Minha mãe me colocou e me manteve no caminho da fé e das tradições religiosas que hoje dão sentido ao meu olhar sobre o mundo. Ela me ensinou a ser uma mulher negra de axé. Foi amiga, mas antes de tudo foi Mãe. Instruiu-me, por metáforas, a enxergar bondades e maldades das pessoas ao meu redor. Sempre foi sabiamente atenta.

Eu já adulta e ela carinhosamente trazia um docinho, uma bananada ou uma paçoca - comprada no vendedor ambulante do ônibus - para me presentar, na volta do trabalho. Assim, mantinha meu lado criança e nossa conecção de mulheres meninas, no compartilhar do doce, ao final da 


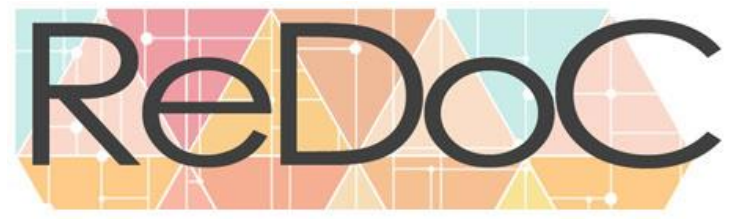

\section{Revista Docência e Cibercultura}

noite. Mulher que me levava de Duque de Caxias à capital, do Rio de Janeiro, para conhecer a cidade. Assim, me fazia entender que o mundo era maior que minha rua e meu bairro. Desta forma, me fez uma andarilha. Ela já sabia que em seria uma mulher de caminhos e estradas.

Do terceiro galho surgem vários que são as mulheres negras do movimento social. Aquelas com as quais aprendi a ser mulher negra ativista. Uma delas é Sandra Bello - hoje vivendo na Alemanha - me ensinou a ser articuladora, a discutir politicamente sobre nossos direitos e reivindicar e denunciar os racismos e sexismos. Certa vez, quando organizávamos o primeiro encontro de Mulheres Negras do Estado do Rio de Janeiro, em 1987, tivemos um grande apoio financeiro e logístico do gabinete de uma deputada branca feminista do estado. Era nossa primeira experiência, no Brasil de realizar um encontro de mulheres negras sem homens e sem mulheres brancas. Algumas assessoras da referida deputada manifestaram desejo de ir ao encontro e argumentavam que afinal haviam sido grandes responsáveis pela realização do evento. Não aceitavam serem deixadas de fora daquele momento histórico. Naquela oportunidade Sandra disse: - Agora é hora de vermos a verdadeira parceria. Se ela realmente existe, vão entender que este momento é nosso e deve ser respeitado.

Pelas mãos de Sandra me iniciei no amor às mulheres com alma e corpo. Também reaprendi a subir morros e comunidades no Rio de Janeiro. Nascida na Baixada Fluminense, acabei assimilando que os morros e favelas eram regiões perigosas às quais deveria evitar.

Antes de Sandra eu consegui saber que esta máxima do perigo não era real, através de minha participação no Bloco Afro Agbara Dudu, de Madureira, no início dos anos oitenta. Vera Mendes. Dinha, Márcia, Néia, Sílvia e as muitas mulheres do Agbara me levaram a subir morros e vielas no ativismo político cultural daquele grupo que arrombava as fronteiras entre morro e asfalto. Mas, foi com Sandra Bello que tive maiores vivências em comunidades, permanecendo inúmeras vezes no morro dos Cabritos.

Meu Baobá tem galhos e flores com Geni Oliveira, mulher atuante na Baixada Fluminense. Com ela, conheci várias cidades da região onde nasci e até hoje, sigo pouco familiarizada. Saberia ainda menos, caso não houvesse sido levada por Geni a encontrar, conversar, ouvir e ser ouvida por mulheres negras das cidades que margeiam a capital do Estado. Participei de 
várias reuniões com a presença de Geni Oliveira. Em algum momento, ela tomava a palavra e fazia uma análise de conjuntura atenta a nos conduzir as reflexões e caminhos de luta. Num jeito simples, com palavras precisas e ponderações esclarecedoras, ela ia nos ajudando na luta coletiva.

Certa vez, numa das nossas infindáveis conversas de bar, após cada reunião. Geni disse: Ninguém financia revolução. Ali, aprendi que ao escrever projetos para serem financiados, temos que pensar ações e vocabulários a serem relatados, sob pena da não obtenção dos recursos. Hoje, esta conversa segue comigo, na escrita acadêmica. Diante da pressão que obriga os professores a produzir para publicar parafraseio e penso: "Ninguém publica textos revolucionários".

Um outro galho, nasceu em terras de Sojouner Thuth, Angela Davis e Michele Obama. Minha amiga Gisele Audrey Mills que conheci em 1987, durante uma reunião de mulheres negras. Ela havia trabalhado todo um ano, nos Estados Unidos reunindo a quantia necessária, para viver os doze meses seguintes, fazendo ativismo no Brasil, sobretudo no Rio de Janeiro. Estamos habituados a receber afro estadunidense que vem nos pesquisar para seus trabalhos acadêmicos. Gisele, ao contrário, desejava compartilhar experiências técnicas, sobretudo, oficinas de vídeo e de sonorização.

Na Eco -92, foi a primeira a nos elucidar sobre os usos e utilização de algo novo e revolucionário, para a época: a internet. Explicou-nos e estimulou a ter nossos primeiros emails. Recordo-me dela, na sala do $\mathrm{CEAP}^{2}$, pacientemente nos introduzindo naquele mundo ainda misterioso.

Por seu intermédio e por um projeto coordenado por ela, fiz minha primeira viagem internacional, em mil novecentos e noventa. Nove meses visitando onze estados dos Estados Unidos, coordenados pelo Third World Women’s Project, do IPS (Institute for Police Studies). Foi a oportunidade de trocar e aprender com mulheres negras de diferentes partes do mundo.

\footnotetext{
${ }^{2}$ CEAP- Centro de Articulação de Populações Negras. ONG do movimento negro do Rio de Janeiro, criada em 1989.
} 


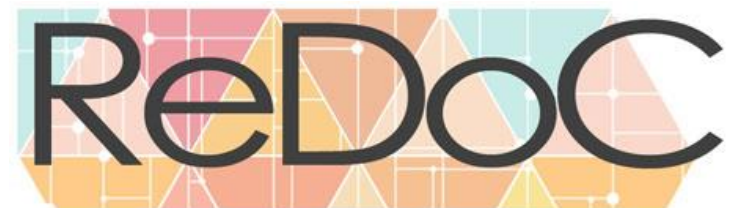

Revista Docência e Cibercultura

Conversei com mulheres negras nos bares, restaurantes, salas de casas, cozinhas, salas de reuniões, auditórios, aeroportos, rodoviárias, passeatas, escolas, universidades, praças e muitas outras ocasiões. Em todas fui descobrindo diferentes valores e visões de mundo, além de estratégias e metodologias de lutas.

Sou de uma geração de ativistas que costumava criticar os que ingressavam nas cátedras acadêmicas. Éramos chamados de traidores e assimiladores das teorias dos brancos. Sofri ainda mais, porque quando entrei no movimento eu já falava inglês fluentemente e era professora da língua. Então, eu além de traidora era disseminadora da cultura do colonizador. Foram anos difíceis. Afinal, era das aulas que mantinha a mim e a minha família com dignidade. Daí, quando me dei conta haviam - se passado vinte e cinco anos desde que eu terminara a universidade. Mestrado e doutorado eram os caminhos prováveis, embora jamais sonhados. Sofri outro baque ao fazer uma especialização e quando falei disto numa reunião, fui desqualificada por uma de nossas lideranças. - Especialização serve para que? Vai ajudar em que na luta?

Mas, ao preparar um currículo para umas palestras organizadas por Gwendolyn Snearl - em Baton Rouge, Estado da Luisiana, nos Estados Unidos - vi que estava a caminho da terceira década desde que terminara o curso de letras. O convite era para realizar uma série de atividades por dois meses, em várias cidades do sul do país, sob a coordenação da LSU (Luisiana State University). Dentre estas, em certa ocasião, ao terminar uma palestra - que foi bastante concorrida com presenças e perguntas - fomos almoçar, Gwendolyn Snearl e eu. Ali, ela me perguntou se eu havia percebido que grandes intelectuais presentes à palestra, haviam feito perguntas a mim e que eu respondera de forma sofisticadamente analítica. Acrescentou também, que eles haviam aprendido muito comigo. Surpreendi-me com a questão. Afinal, eu como ativista e mulher de Ogum, sou daquelas que acreditam que tudo sabem. E que também não se intimidam diante de pessoas tituladas. Ela então arrematou: - Você sabe qual a diferença entre você eles? Todos são PHD e você não. Após esta conversa, decidi regressar e buscar candidatar-me a um programa de mestrado segui no doutorado e recentemente no pósdoutorado. 


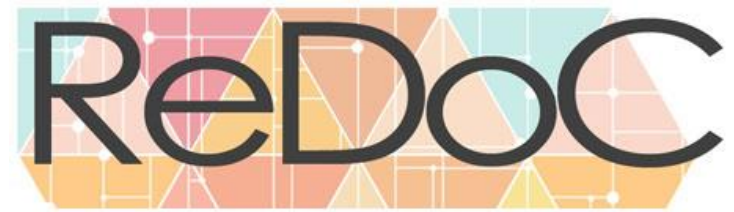

Revista Docência e Cibercultura

Minha amiga Gwendolyn Snearl é pastora numa igreja negra metodista, no Estado de Luisiana. Eu fui criada numa casa de candomblé. Vi minha mãe visitar o quarto de santo de nossa casa de axé, todos os dias antes de dormir, durante quarenta anos. Eu jamais havia feito o mesmo. Gwen, como a chamamos, levanta-se e se ajoelha aos pés da cama, para pedir a Deus que ilumine o seu dia. Antes de deitar, pede uma boa noite e agradece o dia vivido. Apesar dos ensinamentos de minha mãe, foi com Gwendolyn Snearl que reaprendi a conectar-me diariamente com o meu sagrado.

Vivemos numa época de grandes transformações e novos conceitos e categorias são elaborados e constituídos. Dentre estas temos as inúmeras formas de manifestação das sexualidades. É neste mister que entra Neusa das Dores Pereira um dos meus galhos mais frondosos. Ela segue me ensinando a entender que falar de gênero não inclui automaticamente a sexualidade. É à Neuza a quem recorro e cito todas as vezes que tenho dúvidas e desconhecimentos sobre este tema. Certa vez, ouvi Neuza dizer: -Relação homo afetiva eu tenho com minha neta. Somos duas mulheres e nos amamos. Com minha namorada tenho relações homossexuais. Segundo Neuza, dizem relações homo afetivas para não falar em sexualidade. Para não admitir que pessoas do mesmo sexo fazem sexo.

Baobá - embondeiro ou calabaceira - é destas árvores ousadas que não se cansam de tentar alcançar as nuvens, preferencialmente as mais altas. Meu Baobá GENALÓGICO com as Histórias e memórias das mulheres negras que me sustentam não é diferente. Segue avolumando-se e ampliando. Neste processo armazena grandes quantidades da água dos conhecimentos recebidos por todas elas para distribuí-las em terras áridas e ávidas por informações e aprendizados.

Agora, possui frutos e flores que nascem nas universidades onde atuo. São as mulheres que decidem serem minhas orientandas, nos três níveis de formação: graduação, mestrado e doutorado. Balançam-me, desafiam, tencionam, chacoalham e me puxam. Nestes intensos movimentos solidificam minhas raízes que se fincam cada vez mais para se manter de pé. Assim, estes novos e ainda tenros galhos me levam para o alto num infinito que consigo vislumbrar através do engrossar e enroscar de seus galhos que me projetam. 